\title{
An automated disc infiltrometer for infiltration rate measurements using a microflowmeter
}

(Automated disc infiltrometer with microflowmeters)

Moret-Fernández $^{\text {a* }}$, D., C. González ${ }^{\text {c }}$, J. Lampurlanés ${ }^{\text {b }}$, and J. Vicente ${ }^{\text {d }}$

${ }^{a}$ Departamento de Suelo y Agua, Estación Experimental de Aula Dei, Consejo Superior de Investigaciones Científicas (CSIC), PO Box 202, 50080 Zaragoza, Spain.

b Departament de d'Enginyeria Agroforestal, Escola Tècnica Superior d'Enginyeria Agrària, Universitat de Lleida, Av. Rovira Roure, 191, 25198 Lleida, Spain.

c Área de Mecánica de Fluidos, Escuela Politécnica Superior de Huesca, Universidad de Zaragoza, Carretera de Cuarte s/n, 22071 Huesca, Spain

${ }^{\text {d }}$ Departamento de Informática e Ingeniería de Sistemas, Centro Politécnico Superior, Universidad de Zaragoza, C/ María de Luna 1, 50018, Zaragoza, Spain.

* Corresponding author. Tel.: (+34) 976 716140; Fax: (+34) 976716145

E-mail address: david@eead.csic.es 


\section{Acknowledgements}

This research was supported by the Ministerio de Ciencia e Innovación of Spain (grants AGL2007-66320-CO2-02/AGR; 200840I214). The authors are grateful to Valero Pérez for his help in various technical aspects of this study. 


\title{
An automated disc infiltrometer for infiltration rate measurements using a microflowmeter
}

\begin{abstract}
This work presents a new design of disc infiltrometer, which, associated with a microflowmeter (MF) and a solenoid valve set, makes it possible to automate the infiltration rate $(Q)$ measurements at different soil pressure heads $(\psi)$. The MF consists of a 13.8-cm long and $1.5 \mathrm{~mm}$ i.d. pipe, with a pressure transducer connecting the two ends of the MF, inserted in a water-flow pipe that connects the Mariotte tube and the water-supply reservoir of the disc infiltrometer. Water flow is calculated from the head losses in the MF. Changes in $\psi$ in the bubble tower, automatically effected when the infiltration rate reaches steady-state, are controlled by a datalogger connected to four solenoid valves. The new design was tested in laboratory and field conditions, and the results showed that the MF allows the soil water infiltration rates to be correctly estimated for different soil characteristics. The solenoid valve set plus datalogger system satisfactorily monitored the changes in $\psi$ and allowed the measurement time to be optimized.
\end{abstract}

Keywords: Disc infiltrometer; Infiltration rate, Microflowmeter

\section{Introduction}

Over the last two decades, the tension disc infiltrometer has become a popular tool for in situ measurements of soil hydraulic properties in the vadose zone. Originally, this instrument consisted of a base disc jointed to a graduated water-supply reservoir and a bubble tower to impose a negative pressure head $(\psi)$ at the base disc (Perroux and 
White, 1988). The soil hydraulic properties are usually calculated from infiltration rates at steady-state, which are calculated from the drop in water level in the water-supply reservoir. Cumulative soil water-infiltration curves obtained with disc infiltrometers were initially measured by visually noting the drop in water level in the water-supply reservoir. This tedious method, however, was subsequently improved by Constantz et al. (1987), Ankeny et al. (1988) and Casey and Derby (2002), who used pressure transducers to monitor drops in the water level. Similarly, Moret et al. (2004) developed an automated method of measuring the changes in water level in the water-supply reservoir by means of a long three-rod coated Time Domain Reflectometry (TDR) probe vertically inserted in the water-supply reservoir. However, this design, which uses a low-capacity water-supply reservoir, has the disadvantage that the infiltration measurements have to be stopped to refill the reservoir when long-term infiltration experiments are performed. This limitation was partially overcome by Moret-Fernández and González (2009), who, using an infiltrometer with the infiltration disc separated from a high-capacity water-supply reservoir, calculated the infiltration rates from the head losses in the water-flow pipe that connects the water-supply reservoir with the disc of the infiltrometer. However, this new method requires the water-flow pipe to be completely extended on the soil surface in a straight line; otherwise, additional undesirable pressure losses can be included.

Recent advances in the disc infiltrometry technique have been applied to new systems to automate the changes in $\psi$ in the bubble tower by incorporating a set of solenoid valves into a classical disc infiltrometer (Spongrova et al., 2009; Kechavarzi, et al, 2009). However, this system, which automated changes in $\psi$ at predetermined time intervals, cannot control the time at which $Q$ reaches the steady-state. 
The objective of this paper is to present a microflowmeter device which, associated with a disc infiltrometer, allows the soil water infiltration rates to be estimated. This new prototype incorporates a set of four solenoid valves, which, controlled by a datalogger, automatically changes the bubble tower $\psi$ once the steady-state infiltration rate is reached. The new infiltrometer design was tested in laboratory and field conditions under different soil managements.

\section{Material and methods}

\subsection{Theory}

The head losses, $\Delta H_{T}(\mathrm{~m})$, of an incompressible fluid moving along a circular pipe of length $L(\mathrm{~m})$ and internal diameter - i.d. $-D(\mathrm{~m})$ can be approached according to

$$
\Delta H_{T}=\Delta H_{C}+\sum_{1}^{n} \Delta H_{s_{-} i}
$$

where $\Delta H_{C}$ and $\Delta H_{s_{-} i}$ are the continuous and the singular head loss, respectively.

The $\Delta H_{C}$ for a laminar flow along the pipe can be expressed as (Giles et al., 1994)

$$
\Delta H_{C}=\frac{128 v}{\pi g} \frac{Q L}{D^{4}}
$$

where $g\left(\mathrm{~m} \mathrm{~s}^{-2}\right)$ is the acceleration due to gravity, $Q$ the water flow through a circular pipe, and $v$ is the kinematic viscosity $\left(\mathrm{m}^{2} \mathrm{~s}^{-1}\right)$ of the fluid. Eq. (2) is only applicable to laminar flows, in which the Reynolds number (Re) defined as

$$
\operatorname{Re}=\frac{4 Q}{D \pi v}
$$

is lower than 2000. The kinematic viscosity as a function of the water temperature, $t$ $\left({ }^{\circ} \mathrm{C}\right)$, can be described according to $\left(\mathrm{r}^{2}=0.99\right)$ (Moret-Fernández and González, 2009)

$$
v=6.95 \cdot 10^{-10} t^{2}-5.31 \cdot 10^{-8} t+1.78 \cdot 10^{-6}
$$

The singular head loss, $\Delta H_{S}$, (Giles et al., 1994) is expressed according to 


$$
\Delta H_{S}=K_{s} \frac{8 Q^{2}}{\pi^{2} g D^{4}}
$$

where $K_{S}$ is a constant depending on the pipe singularity, for which the values are extracted from tables (Giles et al., 1994).

Applying Eqs. (2) and (5) to Eq. (1) in order to work out the value of $Q$ as a function of $\Delta H_{T}$, we finally obtain

$$
Q=\frac{-\frac{128 v L}{\pi g D^{4}}+\left[\left(\frac{128 v L}{\pi g D^{4}}\right)^{2}+\frac{32 \Delta H_{T}\left(\sum_{i}^{n} K_{S i}\right)}{g \pi^{2} D^{4}}\right]^{1 / 2}}{\frac{16\left(\sum_{1}^{n} K_{S i}\right)}{g \pi^{2} D^{4}}}
$$

where $K_{S i}$ is the $K_{S}$ value for each of the $i$ singularities existing in the pipe.

\subsection{Infiltrometer design and microflowmeter}

The disc infiltrometer used in this study (Moret and Arrúe, 2005) consists of a double Mariotte system where the disc plus Mariotte tube, the bubble tower and the watersupply reservoir are separated from one another (Fig. 1).

This prototype has an independent, high-capacity water-supply reservoir that consists of a cylindrical tank (12.5 cm high and $15 \mathrm{~cm}$ in internal diameter, i.d.) joined at the base to a vertical tube, $30 \mathrm{~cm}$ long and $3.2 \mathrm{~cm}$ i.d., closed at the bottom. A water-flow pipe (50 $\mathrm{cm}$ long and $1 \mathrm{~cm}$ i.d.) connects the bottom of the water-supply reservoir with the base of the Mariotte tube (32 $\mathrm{cm}$ high and $3.37 \mathrm{~cm}$ i.d.), which is assembled on a base disc of $10 \mathrm{~cm}$ diameter. An air-flow pipe (80 $\mathrm{cm}$ long and $0.3 \mathrm{~cm}$ i.d.) connects the top of the Mariotte tube with a moveable air-entry tube that, inserted in the top of the water-supply reservoir, imposes the water level in the Mariotte tube. A bubble tower, 
with four fixed air inlet tubes, supplies four different pressure heads $(-10,-5,-3$ and 0 $\mathrm{cm})$ to the base of the disc through a silicone pipe $(80 \mathrm{~cm}$ long and $0.3 \mathrm{~cm}$ i.d.).

The water flow is measured with a microflowmeter (MF) inserted in the water-flow pipe. This device consists of a tube, $13.80 \mathrm{~cm}$ in length and $0.15 \mathrm{~cm}$ in i.d., attached at the two ends to two tubes $5 \mathrm{~cm}$ in length and $1 \mathrm{~cm}$ in i.d. A bridge-pipe with a $\pm 0.5 \mathrm{psi}$ differential pressure transducer, PT, (model 26PCDFA6D, Microswitch, Honeywell) connects the two 5 -cm-long and 1-cm-i.d. tubes $2 \mathrm{~cm}$ from their respective ends. The PT is finally connected to a datalogger (CR1000, Campbell Scientist Inc.). Under static conditions, the pressure head measured in the MF is constant. However, under dynamic conditions, the pressure measured in the MF increases with $Q$.

A set of four solenoid valves were connected to the air inlet in the four tubes of the bubble tower. Each solenoid valve is controlled through a digital I/O port of the CR1000 used as a control output with the PortSet() instruction. Due to the limited drive capacity of the port an external relay is used to drive each valve. As the CR1000 has 8 digital I/O ports it can control up to 8 valves.

The changes in $\psi$ in the bubble tower, effected when $Q$ reaches steady-state, are controlled by a datalogger program that switches the solenoid valves. The water flow is considered to be in steady-state when the changes in pressure measured by the PT at pre-fixed intervals of time, generally 5 seconds, are lower than $0.05 \mathrm{~cm}$ a defined number of times (10 to 4 scans typically).

The water temperature during the infiltration experiments is measured with a thermocouple sensor which, connected to the datalogger, is inserted in the water-flow pipe just before the MF.

\subsection{Microflowmeter calibration}


A first laboratory experiment was performed to calibrate the microflowmeter method for $Q$ estimations. The experimental design consisted of a Mariotte water-supply reservoir (clear plastic tube $75 \mathrm{~cm}$ in height and $3.7 \mathrm{~cm}$ in i.d.) connected, through a 3 mm i.d. pipe, to a MF that poured the water at atmospheric pressure. The reservoir had a \pm 1 psi PT (model 26PCDFA6D, Microswitch, Honeywell) inserted at the bottom (Casey and Derby, 2002). A microflowmeter of $13.80 \mathrm{~cm}$ length and $0.15 \mathrm{~cm}$ i.d. was first calibrated. The air inlet in the Mariotte water-supply reservoir comprised a silicone pipe (3 $\mathrm{mm}$ i.d. and $80 \mathrm{~cm}$ length) inserted $3 \mathrm{~cm}$ above the water outlet tube in the Mariotte tube, and connected to a bubble tower that supplied four different tensions $(-10,-5,-3$ and $0 \mathrm{~cm})$. The $K_{S}$ values for the singular head loss $\left(\Delta H_{S}\right)$ of the MF ranged between 0.3 and 1 (Giles et al., 1994).

A total of twenty-four different $Q$ (from 0.23 to $2.73 \mathrm{~L} \mathrm{~h}^{-1}$ ), monitored from the drop in water level in the water-supply reservoir, were used to calibrate the MF. For a single opening of the water outlet pipe, four different $Q$ were obtained as a function of the tension supplied by the bubble tower. The tension was automatically controlled by the solenoid valve set plus datalogger, as described above. The changes in $\psi$ were activated when the differences in the average pressure measured by the PT of the MF were lower than $0.05 \mathrm{~cm}$ during ten time intervals. The scanning time interval of the datalogger was 5 seconds. The water temperature was measured with a thermocouple installed in the water-flow pipe just before the MF (Fig. 2). This same experiment was repeated using an MF $5.70 \mathrm{~cm}$ long and $0.15 \mathrm{~cm}$ in i.d.

\subsection{Infiltration measurements}

A series of infiltration measurements in soil column and field experiments were conducted to verify the viability of the MF for infiltration rate measurements and the 
solenoid valve set system for automating the tension change. To this end, a modified Fig. 1 infiltrometer design, which used a clear plastic tube water-supply reservoir (75 cm height and $3.7 \mathrm{~cm}$ i.d.), was used. The $Q$ measured from the drop in water level in the water-supply reservoir was compared with the corresponding $Q$ measured with a MF of $13.8 \mathrm{~cm}$ length and $0.15 \mathrm{~cm}$ i.d.

Two measurements were made in a laboratory using a 2-mm sieved loam soil. In the field, infiltration was measured twice on five different soils (Table 1). The soil dry bulk density $\left(\rho_{b}\right)$ and the prior volumetric water content of the soil were determined by the core method (core dimensions of $50 \mathrm{~mm}$ diameter and $50 \mathrm{~mm}$ height). All the infiltration measurements were performed on the soil surface after removing the surface soil crust. The base disc of the infiltrometer was covered with a nylon cloth of $20-\mu \mathrm{m}$ mesh, and a thin layer of commercial sand was used to ensure good contact between the disc and the soil. The initial pressure head of the MF, needed to calculate $\Delta H_{T}$, was recorded when no water flow was observed through the water-flow pipe. Four different $\psi(-10,-5,-3$ and $0 \mathrm{~cm})$ were used, and only infiltration measurements during the steady-state water flow were considered. The scanning time interval of the PT measurement for both the water-supply reservoir and the MF was 5 seconds. The $\psi$ of the bubble tower changed automatically when the variation in pressure measured in the MF during ten intervals of time was lower than $0.05 \mathrm{~cm}$. The water temperature was also recorded as described above.

\section{Results and discussion}

The effective i.d. of the 5.7- and 13.8-cm long MF estimated from the laboratory calibration experiment were 0.156 and $0.155 \mathrm{~cm}$, respectively. The Reynolds number (Eq. 3) calculated for the different $Q$ and the two different MF used in the laboratory 
and field experiments was always lower than 2000, which indicates that the $Q$ in the MF always had a laminar flow.

The excellent correlation observed in the laboratory experiment (where no soils were used) between the $Q$ measured from the drop in water level in the water-supply reservoir and the corresponding values calculated from the $13.8 \mathrm{~cm}\left(\mathrm{y}=1.004 \mathrm{x} ; \mathrm{r}^{2}=\right.$ 0.997; RMSE $=0.066 ; \mathrm{SD}=0.013)$ and $5.7 \mathrm{~cm}\left(\mathrm{y}=0.977 ; \mathrm{r}^{2}=0.989 ; \mathrm{RMSE}=0.066\right.$; $\mathrm{SD}=0.015$ ) long MF (Eq. 6) demonstrates that the MF can be a reliable method for infiltration rate measurements using the disc infiltrometry technique. For each particular pressure head, the $Q\left(\mathrm{l} \mathrm{h}^{-1}\right)$ calculated from the water level drop corresponded to the regression line slope for the last steps of the cumulative water flow curve. For the MF method, the $Q$ value was calculated from the average pressure head losses recorded in the same time interval.

The good temporal correspondence between the linear correlation of the drop in water level measured in the water-supply reservoir and the flat section of the pressure head in the MF obtained in the calibration experiment (Fig. 2a) indicates that the solenoid valve set plus datalogger system can efficiently detect the time when the infiltration rate reaches steady-state, and consequently activate the mechanism to automatically change the $\psi$ of the bubble tower.

The comparison between the instantaneous water flow rates $\left(\mathrm{l} \mathrm{h}^{-1}\right)$ estimated with the MF and those values calculated from the drop in water level in the laboratory experiments shows that $Q$ values measured with MF are significantly more stable than the corresponding values calculated by the water reservoir method (Fig. 2a). These discrepancies are due to the fact that $Q$ obtained from the drop in water level is calculated from the derivative of the cumulative water flow curve, which increases the sensitivity of $Q$. The large dispersion of water flow rates measured in the field 
experiments from the drop in water reservoir level prevented these measurements from being plotted in Figure 2b.

The excellent correlation (RMSE $=0.013 \mathrm{~L} \mathrm{~h}^{-1}$ ) observed in the soil column and field measurements between the $Q$ obtained from the drop in water level in the water-supply reservoir and the values calculated with the 13.8-cm-long MF (Eq. 6) (Fig. 3) demonstrates that this new method is accurate enough to estimate infiltration rates for a large range of soil characteristics (Table 1). The percentage difference between the $Q$ estimated from the water-supply reservoir and the values calculated with the MF increases as the water flow through the MF decreases (Fig. 4). This disagreement, which could discredit the MF method, should not only be attributed to limitations in the MF at low $Q$, but also to errors made in the calculation of the infiltration rate from the drop in the reservoir water level (i.e. Fig. 2a). This limitation, however, could be overcome by lengthening the scanning time interval of the drop in reservoir water level or by increasing the infiltration rates using infiltrometers with a higher disc diameter.

As observed in the laboratory and field experiments, the solenoid valve set plus datalogger and disc infiltrometer system can satisfactorily identify the time when the infiltration rate reaches steady-state by analysing the flat sections of the pressure curve measured with the MF. Once this time has been detected, the system can automatically change the $\psi$ of the bubble tower (Fig. 2).

\section{Conclusions}

This paper presents a microflowmeter (MF) device which, associated with a disc infiltrometer and a set of solenoid valves, makes it possible to automate the estimation of the soil water infiltration rates at different $\psi$. The laboratory and field experiments have shown that the method can be a viable alternative for measuring infiltration rates 
with disc infiltrometers. In comparison to the classic Perroux and White (1988) prototype, the method proposed here allows a high-capacity water-supply reservoir to be used and the instantaneous soil water infiltration rate to be determined. Compared to the Moret-Fernández and González (2009) prototype, the MF method allows:

1. Use of a water-flow pipe that should not be completely extended in a straight line on the soil surface.

2. Measurements of the water temperature just before the MF, which allows more accurate calculations of $Q$. Further, in situ measurement of water temperature is important to field experiments, since water temperature also affects the water movement into the soil.

3. The solenoid valve set plus datalogger system allows the changes in $\psi$ in the bubble tower to be automated and reduces the measurement time. Additional pressure heads can be measured by incorporating new solenoids valves.

4. Elimination of interference in the water level measurements caused by bubbling inside the water-supply reservoir.

However, compared to the Perroux and White (1988) disc infiltrometer, which is widely used because of its simplicity and ease of use, the design presented here, which has more tubes and cables, may introduce some difficulties for use in the field.

\section{References}

Ankeny, M.D., K.C. Kaspar, Horton, R., 1988. Design for an automated tension infiltrometer. Soil Science Society of America Journal 52: 893-896.

Casey, F.X.M., Derby, N.E., 2002. Improved design for an automated tension infiltrometer. Soil Science Society of America Journal 66: 64-67. 
Constantz, J., Murphy., F., 1987. An automated technique for flow measurements from Mariotte reservoirs. Soil Science Society of America Journal 51: 252-254.

Giles, R.V., Evett, J.B., Liu, C., 1994. Fluid Mechanics and Hydraulics. Ed. McGrawHill Book Company, New York. ISBN 0070205094.

Kechavarzi, C., Spongrova, K. Dresser, M., Matula, S., Godwin, R.J., 2009. Laboratory and field testing of an automated tension infiltrometer. Biosystems Engineering 104: 266-277.

Moret, D., Arrúe, J.L., 2005. Limitations of tension disc infiltrometers for measuring water flow in freshly tilled soils. In: Faz Cano, A., Ortiz, R., Mermut, A.R. (Eds.), Sustainable Use and Management of Soils. Arid and Semiarid Regions. Advances in Geoecology, vol. 36. CATENA-VERLAG Series, Reiskirchen, Germany, pp. 197-204.

Moret-Fernández, D., González, C., 2009. New method for monitoring soil water infiltration rates applied to a disc infiltrometer. Journal of Hydroly 379: 315-322.

Moret, D., López, M.V., Arrúe, J.L., 2004. TDR application for automated water level measurement from Mariotte reservoirs in tension disc infiltrometers. Journal of Hydrology 297: 229-235.

Perroux, K.M., White, I., 1988. Designs for disc permeameters. Soil Science Society of America Journal 52: 1205-1215.

Spongrová, K., Kechavarzi, C., Dresser, M., Matula, S., Godwin, R.J., 2009. Development of an automated tension infiltrometer for field use. Vadose Zone Journal 8: 810-817. 


\section{Figures captions}

Figure 1. Diagram of the new disc infiltrometer design.

Figure 2. Cumulative water flow $\left(\mathrm{cm}^{3}\right)-\bigcirc$ - and water flow rate $\left(\mathrm{l} \mathrm{h}^{-1}\right)-\triangle$ - measured from the drop in water level in the water-supply reservoir and the water flow rate measured with the 13.8-cm long and 1.5-mm i.d. microflowmeter - $\bigcirc$ - at four different pressure heads $(\psi)$ (a) in a laboratory calibration experiment, and (b) on a loosened soil after a pass with a mouldboard and a land-roller.

Figure 3. Relationship between the water-flow values measured from the drop in water level in the water-supply reservoir and those calculated by the microflowmeter of 13.8-cm length for all the soil columns and field measurements.

Figure 4. Relationship between the water flows measured with the water reservoir supply ( $\left.\mathrm{Q}_{w S R}\right)$ and the percentage difference between the water flow measured by the water reservoir and the corresponding value estimated by the microflowmeter $\left(\mathrm{Q}_{\mathrm{MF}}\right)$ in the field experiments. 
Table 1. Description, texture, dry bulk density $\left(\rho_{\mathrm{b}}\right)$ and initial volumetric water content $\left(\theta_{\mathrm{i}}\right)$ of the different soils used to test the $14-\mathrm{cm}-$

long microflowmeter for infiltration rate measurements with the disc infiltrometer at $-10,-5,-3$ and 0 cm pressure heads.

\begin{tabular}{llccc}
\hline Soil & Observation & Replications & Texture & $\begin{array}{c}\rho_{\mathrm{b}} \\
\left(\mathrm{g} \mathrm{cm}^{-3}\right)\end{array}$ \\
\hline LSS & Loam 2 mm sieved soil & $\begin{array}{c}\theta_{\mathrm{i}} \\
\left(\mathrm{cm} \mathrm{cm}^{-3}\right)\end{array}$ \\
COF & Compacted soil on olive field & 2 & Loam & 1.25 \\
CAF & Compacted soil on apple tree field & 2 & Loam & 1.46 \\
LR & Loosened soil after a pass with a rotatiller & 2 & Silt loam & 1.03 \\
LM & Loosened soil after a pass with a mouldboard and a land-roller & 2 & Loam & 1.38 \\
SSB & Sandy soil from a seedbed & 2 & Loam & 0.20 \\
\hline
\end{tabular}


Figure 1.

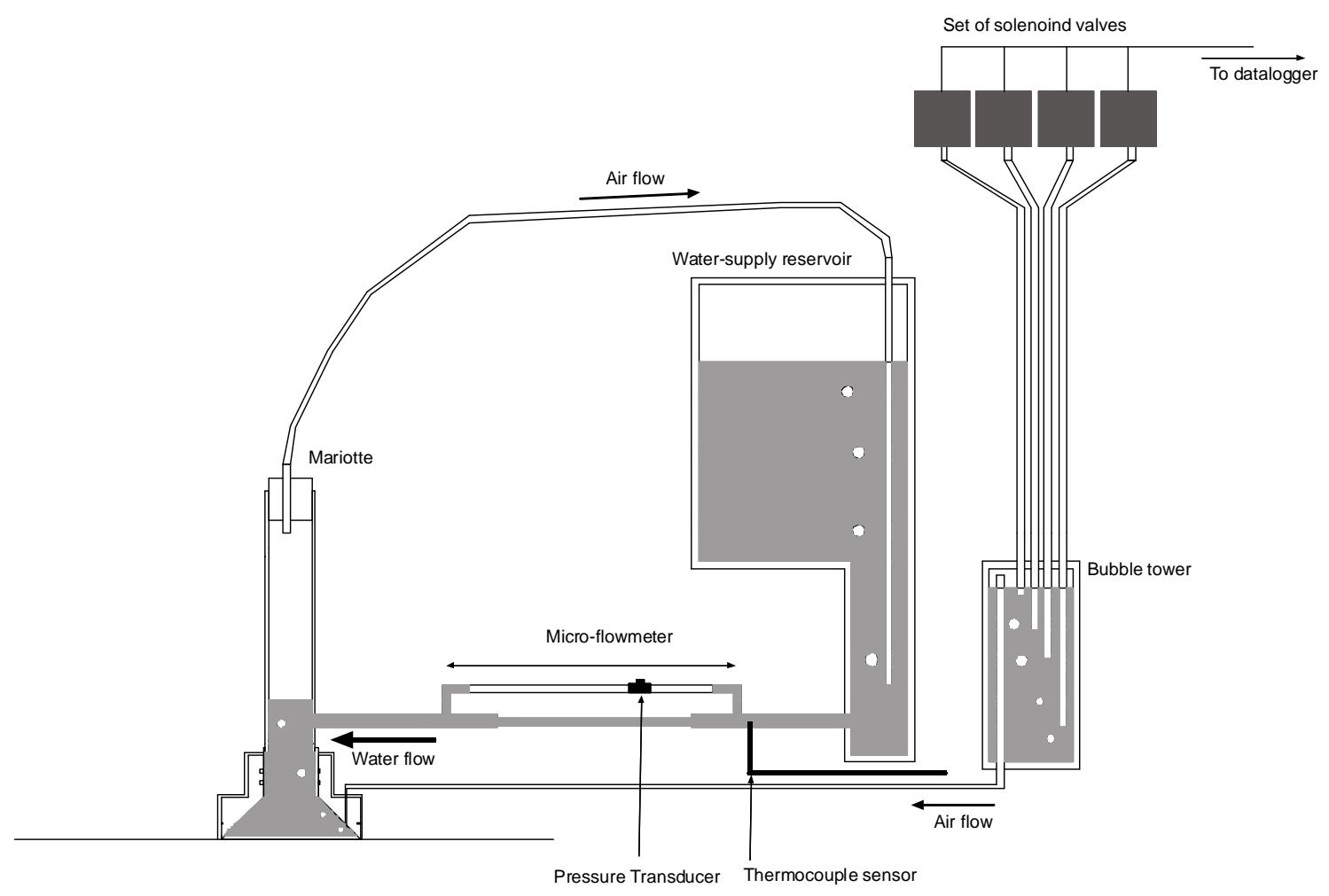


Figure 2.
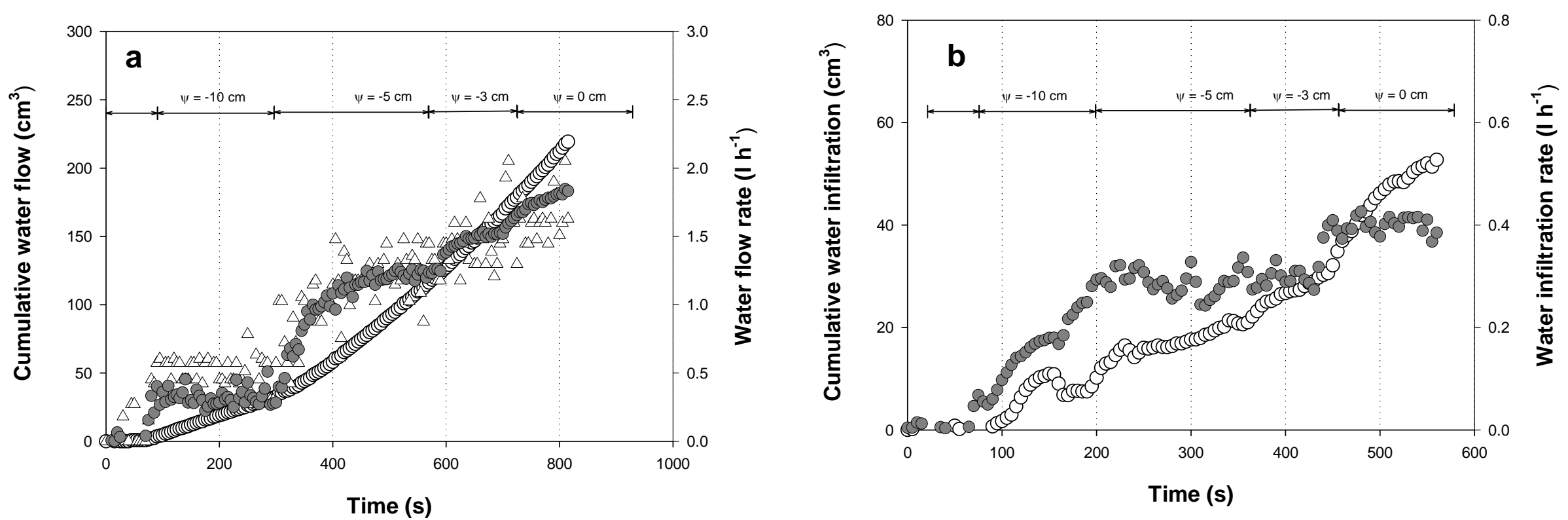
Figure 3.

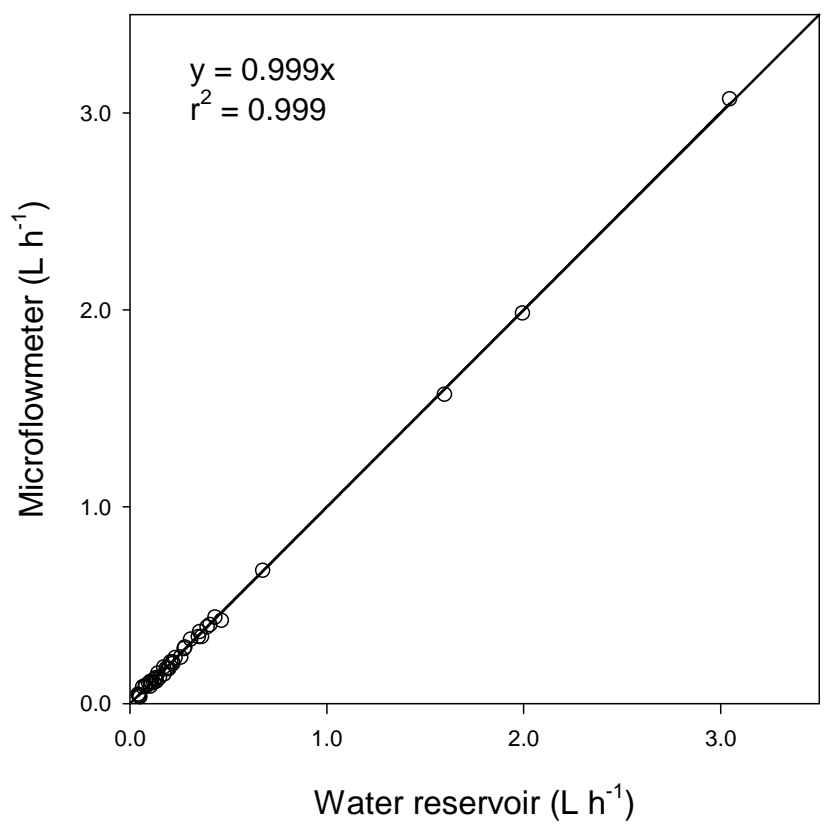


Figure 4.

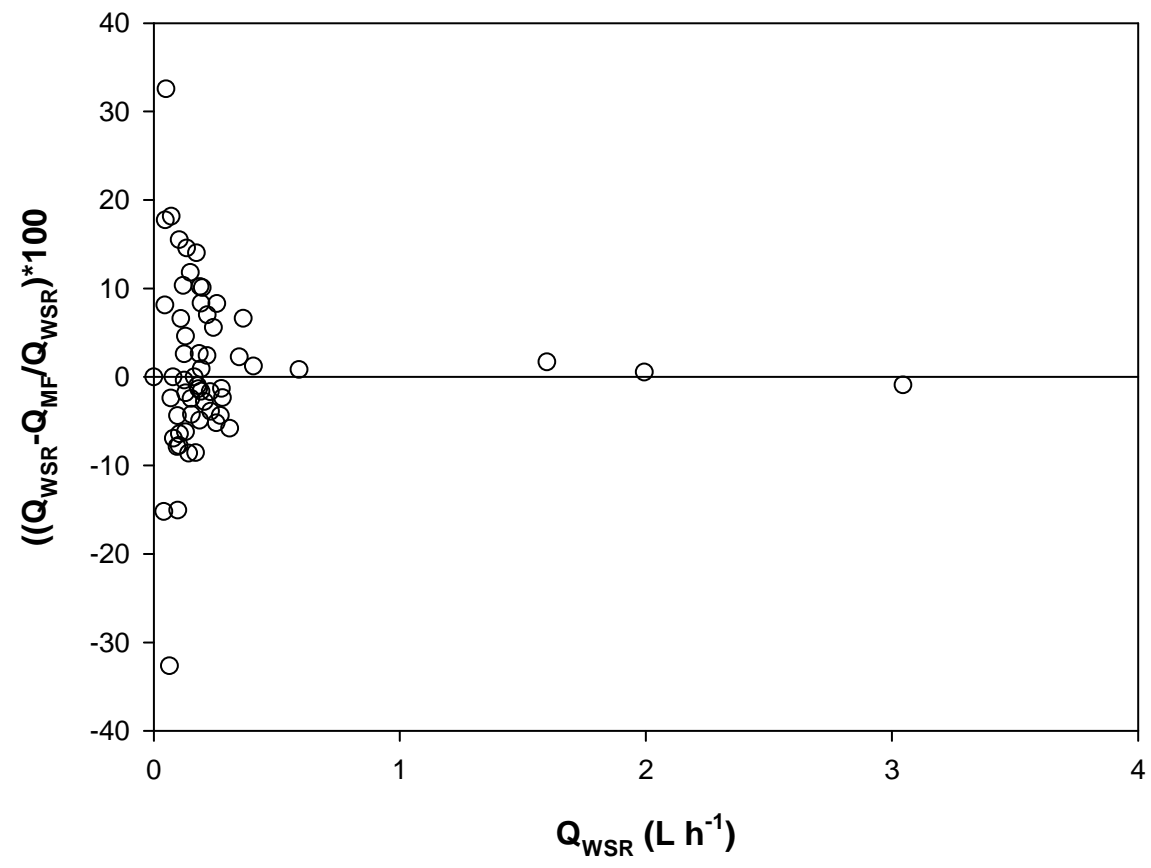

